\title{
Subclinical thyroid disease - treat some while waiting for evidence
}

\author{
Nalla $\mathbf{P} \mathbf{N}^{1}$, Adlan $\mathbf{M} \mathbf{A}^{1}$, Premawardhana $\mathbf{L} \mathbf{D}^{1,2}$ \\ Journal of the Ceylon College of Physicians, 2015, 46, 29-33
}

\section{Introduction}

There has been a significant increase in free thyroxine (free T4) and thyroid stimulating hormone (TSH) testing in clinical practice, because of the universal availability of sensitive, specific and cheap automated assays. It is estimated that approximately $18-25 \%$ of a Western population will have thyroid tests done in a given year. ${ }^{1}$ In the UK, 10 million thyroid tests are performed at a cost of over $£ 30$ million annually. However, such widespread testing sometimes presents practitioners with a clinical conundrum. How should "minor" abnormalities of biochemical thyroid function (i.e. subclinical thyroid disease - STD), be managed in relatively "asymptomatic" individuals? Specialist societies have issued guidelines about investigating and managing STD, as this has become a significant problem in modern clinical practice..$^{2,4}$ Although there is a consensus of sorts, there are some unresolved issues, which need clarification. This lack of clarity is primarily due to a lack of good quality evidence for intervention, for these minor TSH abnormalities.

\section{How common is subclinical thyroid disease?}

Subclinical hypothyroidism ( $\mathrm{SCH}$ ) - Isolated elevation of TSH (with free T4 within the reference range), is estimated to occur in $4-20 \%$ of adults but is influenced by gender, race, iodine status and the concomitant use of medication. ${ }^{5}$ In the USA the prevalence of $\mathrm{SCH}$ was $4.3 \%$ in NHANES III, but $9.5 \%$ in the study of subjects attending health fairs in Colorado. However, the effect of increasing age is noteworthy. The NHANES III data indicate a rise in TSH with age - the $95^{\text {th }}$ percentile for TSH in healthy 70-90 year old American subjects, was as high as 6-9 $\mathrm{mIU} / \mathrm{l}$.

Subclinical hyperthyroidism (SHyper) - SHyper is less common - NHANES III indicating a prevalence of $0.7 \%$

\footnotetext{
${ }^{1}$ Aneurin Bevan University Health Board, Section of Endocrinology, Department of Medicine, YYF Hospital,Caerphilly, CF82 7EP UK.

${ }^{2}$ Cardiff and Vale University Health Board, Centre for Endocrine and Diabetes Sciences, C2 Link, University Hospital of Wales, Heath Park, Cardiff, CF14 4XN UK.

Corresponding author: LDP,

E-mail: premawardhanald@cardiff.ac.uk
}

with a TSH below $0.1 \mathrm{mIU} / \mathrm{l}$ and $1.8 \%$ with a $\mathrm{TSH}$ below $0.4 \mathrm{mIU} / \mathrm{l} .{ }^{6}$ Similar figures were found in the UK. ${ }^{7}$ In all these populations, mild TSH suppression is more common than complete suppression below $<0.1 \mathrm{mlU} / \mathrm{l}$. Age and gender increase the prevalence of SHyper, but iodine deficiency increases it significantly $-9.8 \%$ in Denmark. ${ }^{8}$ Activating mutations of the TSH receptor following constant TSH stimulation seems to be the mechanism responsible for this increase.

The common causes of STD are well known (Table 1). In this review we aim to clarify some features of STD with regard to its consequences, threshold and benefits of treatment, and discuss some special situations. However, we wish to acknowledge that this review is not a comprehensive analysis of STD.

\section{(1) Consequences of STD}

\section{(a) Progression to clinical disease}

No decisions about treatment should be made on a single abnormal TSH level, as levels normalize in about 15-65\% spontaneously. Of those with persistent abnormalities, more than three quarters with $\mathrm{SCH}$ have TSH levels between 5-10mIU/l i.e. mild SCH. ${ }^{9}$ It is known that serum TSH $>10 \mathrm{mIU} / \mathrm{l}$, the female gender and the presence of thyroid peroxidase antibodies (TPOAb) are all associated with progression to clinical hypothyroidism. The annual rate of progression is estimated to be $4 \%$ (raised TSH in TPOAb positive women); $2-4 \%$ (raised TSH only); and 1-3\% (TPOAb only). ${ }^{10,12}$

SHyper is often transient and is more common in iodine deficient populations. It is also more common in the female and the elderly. The risk of progression to overt hyperthyroidism is related to the degree of TSH suppression - those with completely suppressed (undetectable) TSH, progress more frequently than those with suppressed but detectable levels. ${ }^{13}$ Progression to overt hyperthyroidism is variably reported at below $1 \%$ at 5-7 years ${ }^{7}$ and in another study at $45 \% .^{14}$

(b) Effects on vascular health, bone health and mortality

The effects of STD on vascular and bone health, and all cause mortality are often used to justify intervention in STD. 
Table 1. The causes of subclinical thyroid disease

\begin{tabular}{|c|c|c|}
\hline Diagnosis & Causes & Remarks \\
\hline \multirow[t]{6}{*}{ Subclinical hypothyroidism } & Hashimoto's thyroiditis & $\begin{array}{l}\text { Most common cause } \\
\text { Commonly TPOAb positive* }\end{array}$ \\
\hline & Anti-thyroid drug therapy & Thionamides \\
\hline & Thyroid ablation & $\begin{array}{l}\text { Previous radioiodine therapy or } \\
\text { surgery }\end{array}$ \\
\hline & $\begin{array}{l}\text { Inadequate thyroxine } \\
\text { replacement therapy }\end{array}$ & $\begin{array}{l}\text { During initiation of } \\
\text { therapy specially }\end{array}$ \\
\hline & Drugs impairing thyroid function & Often neglected \\
\hline & External radiation to neck & Very uncommon now \\
\hline \multirow[t]{6}{*}{ Subclinical hyperthyroidism } & $\begin{array}{l}\text { Exogenous thyroid } \\
\text { hormone therapy }\end{array}$ & Most common cause \\
\hline & Nodular thyroid disease & $\begin{array}{l}\text { Multinodular goitre or a } \\
\text { toxic adenoma }\end{array}$ \\
\hline & Graves' disease & TRAb positive usually** \\
\hline & Thyroiditis & Postpartum, subacute or silent \\
\hline & Drugs & 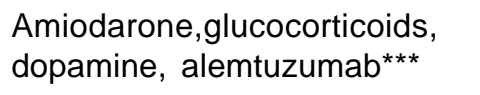 \\
\hline & Pregnancy & $\begin{array}{l}\text { First trimester, multiple } \\
\text { pregnancies or hyperemesis }\end{array}$ \\
\hline
\end{tabular}

* Undetectable TSH

** Suppressed but detectable

$\mathrm{SCH}$ is known to be associated with an increased risk of coronary heart disease (CHD), heart failure, and vascular disease. ${ }^{15,17}$ The risk seems to be greatest in those who develop $\mathrm{SCH}$ at a young age and in those who have a TSH $>10 \mathrm{mIU} / \mathrm{l} .{ }^{18,19}$ The effect on cardiovascular mortality is however inconsistent. Paradoxically, the Leiden study seemed to show a protective effect of raised TSH on cardiovascular death and increased longevity in over 85-year old individuals. ${ }^{20}$

SHyper is associated with increased rates of atrial fibrillation (AF), cardiovascular and all cause mortality (inconsistent), and decreased bone mineral density. The effect of decreased bone mineral density on the incidence of fracture was not consistent. Clearly, the elderly were at higher risk of all three. In addition, other cardiac abnormalities (sinus tachycardia, increased atrial and ventricular premature beats) and a hypercoagulable state have also been reported in SHyper.

\section{(2) Benefits of treating STD}

Given the association of STD with adverse cardiovascular and bone health, and vascular morbidity and mortality, it is intuitive to expect benefits with treatment. However, the lack of large, well-powered prospective randomized controlled trials (RCTs) showing benefits of treatment in STD has made it difficult to formulate clinically relevant and consistent guidance about its management. In fact the US Preventative Services Task Force (USPSTF) recommendations have remained essentially unchanged between 2004 and $2014,{ }^{10}$ as testament to this knowledge gap. The onset of clinical disease (symptoms, signs and biochemical abnormalities) and "systemic effects" as described above, are often invoked as justification for intervention in both types of STD.

But where is the evidence?

(a) Subclinical hypothyroidism - The only RCTs done for $\mathrm{SCH}$ are small, and underpowered, and have resulted in confusing outcomes. However, there is good evidence for improved outcomes for $\mathrm{CHD}$ (systolic and diastolic dysfunction, endothelial function and carotid-intima thickness), particularly in younger subjects, ${ }^{21}$ and for renal preservation in subjects with chronic kidney disease. 
(b) Subclinical hyperthyroidism - In an excellent editorial, Franklyn and Boelaert point to deficiencies in the evidence for the benefits of intervention for SHyper, particularly in relation to cardiovascular disease. ${ }^{22}$ They point to (i) investigators disregarding confounders such as coronary heart disease or heart failure on outcome; (ii) the reliance on a single test for establishing diagnosis and failure to repeat TSH in most studies; (iii) the imperfect nature of thyroxine replacement therapy following radioiodine (RAI) therapy for SHyper, often causing iatrogenic hyperthyroidism or $\mathrm{SCH}$, in a significant minority; (iv) and the serious lack of RCTs.

The difficulties associated with research in the area of STD are well described in two recent reviews. ${ }^{22,23}$ The lack of good quality data hampers progress in this important area of endocrinology.

\section{(3) The threshold for treatment}

Three recent meta-analyses of observational studies have indicated thresholds for intervention for $\mathrm{SCH}$ of $\mathrm{TSH}>10 \mathrm{mIU} / \mathrm{l}$ and for SHyper of TSH of $<0.1 \mathrm{mIU} / \mathrm{l}$.

A TSH level of $>10 \mathrm{mIU} / \mathrm{l}$ is chosen as a threshold for treatment of $\mathrm{SCH}$, because above this level subjects have more frequently, symptoms, increased progression to clinical disease, higher lipid levels, and a greater chance of CHD, heart failure and CHD mortality. All cause mortality was reduced in subjects treated with thyroxine in a re-analysis of the Whickham data. ${ }^{21}$
There is no consensus about treating subjects with milder degrees of $\mathrm{SCH}$. The presence of possible symptoms, TPOAb and other cardiovascular risk factors would tip the balance in favour of treatment in them (Table 2).

As spontaneous remission is unlikely, a TSH level of $<0.1 \mathrm{mIU} / \mathrm{l}$ is taken as the threshold for treatment in subjects with SHyper who are more than 65 years of age. In younger individuals the presence of cardiovascular disease and osteoporosis, would tilt the balance in favour of intervention. Treatment may not be necessary in those with mildly suppressed TSH (0.1 to $0.4 \mathrm{mIU} / \mathrm{l})$. However, in the over 65-year age group the risk of AF may indicate the need for treatment in this group as well (Table 2). Unfortunately there is no RCT evidence for any of these recommendations.

\section{(4) Special situations}

Pregnancy - Most authorities recommend thyroxine replacement even for minor degrees of $\mathrm{SCH}$ in pregnancy, or in women desiring to become pregnant. If local trimester specific TSH ranges are not available, most authorities recommend aiming for TSH levels of 2.5, 3 and $3.5 \mathrm{mIU} / \mathrm{l}$ respectively for the first, second and third trimesters, if necessary with thyroxine replacement. The adverse maternal and foetal effects of $\mathrm{SCH}$ are often cited in support of treating $\mathrm{SCH}$, although evidence is sparse and consists of small intervention studies. However, it should be noted that the only RCT studying thyroxine intervention in pregnant women with $\mathrm{SCH}$ did not show any benefit in cognitive function in children at 3 years. ${ }^{24}$

Table 2. Recommendations for treating subclinical thyroid disease

\begin{tabular}{lll}
\hline Condition & TSH level & Remarks \\
\hline Subclinical hypothyroidism & $1 .>10 \mathrm{mIU} / \mathrm{l}$ & General consensus is to treat \\
& $2.5-10 \mathrm{mIU} / \mathrm{l}$ & $\begin{array}{l}\text { Consider treating those }<65 \text { years of } \\
\text { age; background vascular risk factors; } \\
\text { possible thyroid related symptoms; } \\
\text { pregnancy or desire to become } \\
\text { pregnant; goiter; TPOAb present }\end{array}$
\end{tabular}

Subclinical hyperthyroidism $\quad$ 1. $<0.1 \mathrm{mIU} /\left.\right|^{*}$

2. $0.1-0.4 \mathrm{mIU} / \mathrm{I}^{\star \star}$
General consensus is to treat if over $>65$ years: Consider treating younger subjects with heart disease, thyroid related symptoms and osteoporosis

Consider treating $>65$ years; consider treating $<65$ years if they have thyroid symptoms or heart disease

\footnotetext{
* Undetectable TSH

** Suppressed but detectable
} 
Non-thyroidal illness syndrome (NTIS) - A significant proportion of acutely ill patients will have biochemical thyroid abnormalities. About $15 \%$ of such individuals have isolated TSH changes. Of them, less than half of subjects with more severe thyroid abnormalities such as undetectable TSH levels or TSH $>20 \mathrm{mIU} / \mathrm{l}$ have an underlying thyroid disorder. Often there is no reciprocal change in free T4 or T3 in these individuals. In clinical practice, thyroid hormone or TSH testing is not found to be useful in the acutely ill subject. ${ }^{25}$ If abnormal thyroid tests are found, they need to be repeated about 8-12 weeks after recovery from the acute illness. If abnormalities are persistent, they are unlikely to be due to NTIS, and will need investigations and intervention as discussed above.

\section{(5) Recommendations}

Recommendations for intervention for STD are beset with a lack of good quality evidence. Therefore, there is hardly an evidence base for most recommendations made by professional societies and expert bodies. However, Table 2 contains a summary of current views from Specialist Societies, which the authors follow in their clinical practice.

\section{(6) Conclusions}

There is a major gap in our knowledge about the benefits of intervention in STD, which is not an uncommon disorder. The lack of good evidence in this area is a significant problem for clinicians who manage these patients. However, there are ongoing studies which we hope will give us better information to base future recommendations.

\section{References}

1. Meyerovitch J, Rotman-Pikielny P, Sherf M, Battat E, Levy Y, Surks MI. Serum thyrotropin measurements in the community. Arch Intern Med. 2007; 167: 1533-38.

2. Garber G, Cobin R, Gharib H, Hennessey J, Klein I, Mechanick $\mathrm{J}$, Pessah-Pollack R, Singer P, Woeber K. Clinical practice guidelines for hypothyroidism in adults; co-sponsored by the American Association for Clinical Endocrinologists and the American Thyroid Association. Endocr Pract 2012; 18: 988-1028.

3. Pearce SHS, Brabant G, Duntas L, Monzani F, Peeters RP, Razvi S, Wemeau JL. 2013 ETA guideline; management of subclinical hypothyroidism. Eur Thy J 2013; 2: 215-28.

4. Jonklaas J, Bianco AC, Bauer AJ, Burman KD, Cappola AR, Celi FS, Cooper DS, Kim BW, Peeters RP, Rosenthal MS, Sawka AM. Guidelines for the Treatment of Hypothyroidism: Prepared by the American Thyroid Association Task Force on Thyroid Hormone Replacement. Thyroid 2014; 24 : 1670-751.

5. Cooper DS. Subclinical hypothyroidism. Thy Res Pract 2013; 10: Suppl. S9-11.
6. Cooper DS, Biondi B. Subclinical thyroid disease. Lancet 2012; 379: 1142-54.

7. Vadiveloo T, Donnan PT, Cochrane L, Leese GP. The Thyroid Epidemiology, Audit, and Research Study (TEARS): Morbidity in Patients with Endogenous Subclinical Hyperthyroidism. $J$ Clin Endocrinol Metab 2011; 96: 1344-51.

8. Laurberg P, Pederson KM, Hreidarsson A, Sigfusson N, Iversen E, Knudson PR. Iodine intake and pattern of thyroid disorders; a comparative epidemiological study of thyroid abnormalities in the elderly in Iceland and Jutland, Denmark. J Clin Endocrinol Metab 1998; 83: 765-69.

9. Somwaru LL. Rariy CM, Arnold AM, CappolaAR. The natural history of subclinical hypothyroidism in the elderly: the cardiovascular health study. J Clin Endocrinol Metab 2012: 97: 1962-69.

10. Ruggae JB, Bougatsos C, Chou R. Screening and treatment of thyroid dysfunction: an evidence review for the US Preventive Services Task Force. Ann Intern Med 2015; 162: $35-45$.

11. Vanderpump MP, Tunbridge WM, French JM et al. The incidence of thyroid disease in the community: a twentyyear follow up of the Whickham survey. Clin Endocrinol (Oxf) 1995; 43: 55-68.

12. Walsh JP, Bremner AP, Feddema P. Leedman JP, Brown SJ, O'Leary P. Thyrotrophin and thyroid antibodies as predictors of hypothyroidism; a 13 year longitudinal study of a community based cohort using current immunoassay techniques. J Clin Endocrinol Metab 2010; 95: 1095-104.

13. Das G, Ojewuyi TA, Baglioni P, Geen J, Premawardhana LD, Okosieme OE. Serum thyrotrophin at baseline predicts the natural course of subclinical hyperthyroidism. Clin Endocrinol (Oxf). 2012; 77: 146-51.

14. Diez JJ, Iglesias P. An analysis of the natural course of subclinical hyperthyroidism. Am J Med Sci 2009; 337: 22532.

15. Hak AE, Pols HA, Visser TJ, Drexhage HA, Hofman A, Witteman JC. Subclinical hypothyroidism is an independent risk factor for atherosclerosis and myocardial infarction in elderly women: the Rotterdam Study. Ann Intern Med 2000; 132: $270-8$.

16. Imaizumi M, Akahoshi M, Ichimaru S, Nakashima E, HidaA, Soda M, Usa T, Ashizawa K, Yokoyama N, Maeda R, Nagataki $\mathrm{S}$, Eguchi K. Risk for ischemic heart disease and all- cause mortality in subclinical hypothyroidism. J Clin Endocrinol Metab 2004; 89: 3365- 70.

17. Walsh JP, Bremner AP, Bulsara MK, O'Leary P, Leedman PJ, Feddema $P$, Michelangeli V. Subclinical thyroid dysfunction as a risk factor for cardiovascular disease. Arch Intern Med 2005; 165: 2467-72.

18. Rodondi N, Newman AB, Vittinghoff E, de Rekeneire N, Satterfield S, Harris TB, Bauer DC. Subclinical hypothyroidism and the risk of heart failure, other cardiovascular events, and death. Arch Intern Med 2005; 165: 2460-6.

19. Razvi S, Shakoor A, Weaver JU, Vanderpump M, Pearce $\mathrm{SH}$. The influence of age on ischaemic heart disease and mortality in subclinical hypothyroidism - a meta-analysis. J Clin Endocrinol Metab 2008; 93: 2998-3007.

20. Rodondi N, den Elzen WP, Bauer DC, CappolaAR, Razvi S, Walsh JP, Asvold BO, lervasi G, Imaizumi M, Collet TH, 
Bremner A, Maisonneuve $P$, Sgarbi JA, Khaw KT, Vanderpump MP, Newman AB, Cornuz J, Franklyn JA, Westendorp RG, Vittinghoff E, Gussekloo J. Thyroid Studies Collaboration: Subclinical hypothyroidism and the risk of coronary heart disease and mortality. JAMA 2010; 304: 1365-74.

21. Razvi S, Weaver J, Vanderpump MP, Peearce SH. The incidence of ischaemic heart disease and mortality in people with subclinical hypothyroidism; a reanalysis of the Whickham cohort. J Clin Endocrinol Metab 2010; 95: 1734-40.

22. Franklyn JA, Boeleart K. Subclinical thyroid disease: where is the evidence? Lancet Diab Endocrinol 2013; 1: 172-3.

23. Goichot B, Pearce SHS. Subclinical thyroid disease: time to enter the age of evidence based medicine. Thyroid 2012; 22: $765-8$.

24. Lazarus JH, Bestwick JP, Channon J et al. Antenatal thyroid screening and childhood cognitive function. N Engl J Med 2012; 306: 493-501.

25. Adlan MA, Neel V, Lakra SS, Bondugulapati LN, Premawardhana LD. Targeting thyroid testing in acute illness; achieving success through audit. J Endocr Invest 2011; 34: 210-13. 